\begin{tabular}{|c|c|c|}
\hline & $\begin{array}{l}\text { ANNALES INSTITUTI SLAVICI } \\
\text { UNIVERSITATIS DEBRECENIENSIS }\end{array}$ & \\
\hline SLAVICA XLVIII & 2019 & DEBRECEN \\
\hline
\end{tabular}

Сергей Шульц

\title{
НЕОСУЖДЕНИЕ И/ИЛИ ПРОЩЕНИЕ: НАБЛЮДЕНИЯ О ТЕОЛОГИИ Л.Н. ТОЛСТОГО НА ФОНЕ ФИЛОСОФИИ И. КАНТА И М.М. БАХТИНА
}

\author{
Non-blame and/or Forgiveness: Observations about L.N. Tolstoy's \\ Theology on the Background of the Philosophy of I. Kant and M.M. Bakhtin
}

\begin{abstract}
The problem of correlation of non-blame and forgiveness in L. Tolstoy's world is put in the context of Kant's and Bakhtin's philosophy. The author comes to the conclusion that for L. Tolstoy non-blame is above forgiveness.
\end{abstract}

Keywords: L. Tolstoy, Kant, Bakhtin, non-blame, forgiveness

Для европейцев мотив прощения - специфически христианский. Он переплетен с мотивом недопустимости осуждения. Второй мотив стал в жизни и в культуре специфически толстовским. Никто так полно и многопланово не тематизировал идею недопустимости всякого осуждения - от мыслительно-словесного до применяемого в карательной машине государства и других институциях, - как Толстой. Неосуждение - это не отказ от некоей оценки вообще, а отказ от негативирующего подхода к другому.

При всей родственности мотивов прощения и неосуждения, при безусловном отсутствии их прямой антиномии, это во многом разные мотивы, о чем пойдет речь.

Заметно преувеличивая черты негатива в толстовском отношении к христианству его эпохи, Н.А. Бердяев вместе с тем констатировал: «Он - страшный враг христианства и предтеча христианского возрождения» [БЕРДяЕВ 1994: 466].

Отношение Л. Толстого к православию и вообще к христианству было сложным, что восходит к индивидуально толстовскому типу субъективности. Субъективность (не субъективизм, не имеющий никакого отношения к субъективности) Толстого не позволяла ему принять общее и общепринятое. Толстой искал своего - но только потому, что он хотел личностно все освоить и принять, личностно, из себя. У Толстого получился некий собственный проект и вариант христианства, в чем, действительно, некое сходство с Лютером. Однако главное отличие от Лютера в том, что Толстой свой проект никому не предлагал в социальном измерении, т.е. Толстой не организовывал никаких общественно-религиозных движений, толстовцев он не принял. Протестантизм же был (и есть) движением общественным - хотя он подавал себя как движение религиозное или, в крайнем случае, общественно-религиозное. Но протестантизм всегда имел и имеет к религиозности довольно косвенное отношение, так было и на раннем его этапе. Вновь повторим: протестантизм - движение 
социальное, в социальных обличениях «папизма» он и возник, а догматы Римско-католической церкви просто попутно переписал, имея в виду угодить сугубо общественным запросам.

Еще в раннем рассказе «Из записок князя Д. Нехлюдова. Люцерн» Толстой напишет, подразумевая описанную им сюжетную ситуацию всеобщих насмешек над «маленьким тирольцем»-музыкантом, вообще пренебрежения людей друг к другу: «Ежели бы только человек выучился не судить и не мыслить резко $<\ldots>$ и не давать ответы на вопросы, данные ему только для того, чтобы они вечно оставались вопросами!» [ТОЛСтой 1928-1958 т.5: 24].

Эпиграф к «Анне Карениной» «Мне отмщение, и Аз воздам» [Толстой 1928-1958 т.18: 3] имеет в виду прежде всего то, что человек не может судить и наказывать другого, а только Бог - в эсхатологической перспективе.

В финале романа «Воскресение» Толстой сходно формулирует устами Нехлюдова, комментирующего евангельские изречения: «Первая заповедь (Мф. V, 21-26) состояла в том, что человек не только не должен убивать, но не должен гневаться на брата, не должен никого считать ничтожным, «рака», а если поссориться с кем-либо, должен мириться, прежде чем приносить дар Богу, то есть молиться〉 (выделено Толстым) [Толстой 1928-1958 т.32: 443].

В «Воскресении» Нехлюдов постоянно рассуждает о необходимости прощения - рядом с тезисом о недопустимости всякого осуждения: «... единственное и несомненное средство спасения от того ужасного зла, от которого страдают люди, состояло только в том, чтобы люди признавали себя всегда виноватыми перед Богом и потому не способными ни наказывать, ни исправлять других людей» [Толстой 1928-1958 т.32: 442].

Таким образом, категория вины (и соответствующего ей прощения) по преимуществу закрепляется Толстым за отношением человека к Богу, а категория неосуждения («не должен гневаться на брата, не должен никого считать ничтожным»; «ни наказывать, ни исправлять») в основном фиксируется как императив межчеловеческого общения.

Внутренний предсмертный монолог Анны в «Анне Карениной» показывает, что под отказом от «исправления» Толстой подразумевает, конечно, нечто гораздо более широкое, чем узко-юридический план. В частности, рассуждая о своих взаимоотношениях с Вронским, героиня думает: «Мы жизнью расходимся, и я делаю его несчастье, он мое, и переделать ни его, ни меня нельзя. Все попытки были сделаны, винт свинтился» [ТОлстой 1928-1958 т.19: 344].

Но неоконченные толстовские «Записки сумасшедшего» свидетельствуют, что и перед Богом Толстому трудно чувствовать в себе вину, что в минуту отчаяния он скорее готов возложить вину на самого Бога [см: ШульЦ 2001].

В идеале контакт индивида и Абсолютного Другого возможен скорее в их внутреннем диалоге-неосуждении: это вывод «поверх» «Записок сумасшедшего», т.е. он непредвидим изначально автором-героем. Здесь уместно процитировать мнение Н.А. Бердяева о Толстом: «Гениальные религиозные переживания и недаровитые, банальные религиозные мысли!» [БЕРДяЕВ 1994: 463]. 
Однако для читателя Толстого должны быть существенны прежде всего те «религиозные мысли», которые отражают смысл непосредственно «религиозных переживаний» писателя, а не какие-то его отвлеченные «мысли» (да и те все же по-своему даровиты и небанальны).

По справедливому мнению М.М. Бахтина, основной тезис Толстого в «Воскресении»: «недопустимость какого бы то ни было суда над человеком <... Нет призванных судей и не может их быть, ибо суд сам по себе, каков бы он ни был, есть злая и лживая выдумка людей» [БАХТИН 2000: 193].

С дальнейшим же развитием бахтинской мысли трудно согласиться: «Этот тезис оправдывается прежде всего основным сюжетным положением романа: Нехлюдов, оказавшийся в законном порядке присяжным заседателем в процессе Масловой, т.е. судьею Катюши, на самом деле является виновником ее гибели» [БАХТИН 2000: 193].

Вывод о недопустимости осуждения, действительно, выношен Нехлюдовым благодаря его приверженности своему «душевному делу». Вывод не основывается только на внешних перипетиях сюжета. Тезис Толстого - среди центральных в его художественно-философско-религиозном мире в целом. Поэтому совершенно непонятно мнение С. Худспит о том, что якобы (конкретно в «Воскресении») «Толстой не совсем удачно объединил критику правосудия со своей философией» [ХУдспит 2005: 33].

Бахтин говорит, что Нехлюдова в «Воскресении» занимают «чисто отрицательные заповеди» [БАХТин 2000: 203]. Однако какими бы те ни были, они остаются в основе евангельскими; ср. эпиграфы к роману, их цитирование и сложное - почти герменевтическое - освоение в тексте. Кроме того, многое зависит от того, что за способ их формулирования и воплощения в жизнь выбран, зависит от контекста толстовской мысли и контекста исторического и жизненного мира - от того, что Бахтин назовет противоабстрактным «событием бытия».

Н.А. Бердяев также обращает особое внимание на роль исполнения заповедей для Толстого (не подчеркивая их «отрицательность»), но философ неправомерно сводит все сложные толстовские идеи в целом - только к «заповедям».

Внимание Толстого к «отрицательным тезисам» связано, очевидно, с кантовской дуальной моделью диалектики. В исключительном внимании к «отрицательности» идей одна из параллелей к Толстому в XX веке - Т.В. Адорно, который, развивая кантовскую модель диалектики, считает факт отрицания более продуктивным. Вспоминается здесь также М. Хайдеггер с его «Отказ не отнимает. Отказ одаривает» [ХАЙДЕГГЕР 1993: 241)] ${ }^{1}$ или П.П. Пазолини со сходным «Отказ всегда был главным жестом» [ПАзОлини 2000: 594]2. В ко-

1 Когда Хайдеггера в 1969 году спросили, напишет ли он когда-нибудь «Этику», мыслитель ответил: «"Этику”? Кто может себе это позволить сегодня и от имени какого авторитета предложить ее миру?» [17, с.152]. В основе высказывания - отказ от идеи осуждения других.

2 Ср. также идею «праведничества без Бога» у А. Камю, также построенную на мысли об «отказе». 
нечном счете дело, однако, не в том, «отрицательны» или «положительны» заповеди, ставимые во главу угла Нехлюдовым и его союзником автором/нарратором, а в их наполнении.

Кроме того, Бахтин противопоставляет «критический момент» у Толстого в качестве якобы более сильного в «Воскресении» «тонам покаяния, прощения, непротивления» в качестве якобы менее «энергичных», менее «сильных» [БАХТИН 2000: 204]. Однако не обстоит ли ситуация у Толстого с точностью до наоборот?

Тезис о неосуждении не зависит от социальных условий, среды, а апеллирует к внутреннему «я» индивида перед лицом других. Именно поэтому у Толстого всегда акцентируется в первую очередь персоналистический и даже индивидуалистический момент, вопреки декларациям автора о «роевой жизни» [см.: Шульц 2002].

В этике Канта постулат о том, что каждый своими поступками задает одновременно образец для другого, обращен в том числе к идее прощения в качестве взаимного «всепрощения». Однако тезис Канта в его системе мышления задает не цельность интерсубъективности, как может показаться, не признание другого в его другости, а, напротив, механическое, почти насильственное «склеивание» человеческого сообщества, при котором один общественный атом получает право диктовать другому правила поведения: поступай, подобно мне. Кант даже пишет о «моральном принуждении» и в связи с этим «уважении не к жизни, а к долгу» [КАНТ 1999: 343; 351].

«Желательное» поведение вроде бы должно вести за собой адекватный ответ, но «адекватности» в этом случае требует и нежелательное поведение - т.е. оно диктует столь же негативное. По наблюдению М. Шелера, критикующего Канта, «если они (конкретные люди. - С.Ш.) впадают в заблуждения, то основанием этого выступает их злая воля, которая, таким образом, никогда не может пребывать «в неповиновении» этим законам, но, скорее, с необходимостью их исполняет» [ШЕЛЕР 1994а: 303] (выделено М. Шелером) - можно сказать, «злая воля» исполняет буквально самый «категорический императив» в качестве пустой формы.

Понятно, что Кант подразумевал идею сознательности и осознанности выбора (в виде «формальных»), но: не только позитивный, а всякий выбор можно осознать внутри себя - это главный аргумент против, в частности, вседействительности всепрощения «по Канту». Ведь последнее, если оно дар, в кантовской ситуации требует ответного дара, а от этого коннотация дара исчезает в обязательности, т.е. противоположности себе. Дар перестает быть даром. Данная ситуация анализировалась первоначально в культурной антропологии на основе анализа архаических ритуалов (см., например, выводы в позднейшей герменевтической работе: [РИКЁР 2010] ${ }^{3}$

3 М. Хайдеггер, понимая мышление как дар, требует от личности не «обязательности», а градуса интенсивного соответствия этому дару [ХАЙДЕГГЕР 2006]. 
Прощение «по Канту» способно невольно втянуть также и в отношения некоей «дурной» зависимости от другого: а как другой отреагирует? А нуждается ли он в этом? А что мне за это будет? И т.п.

Из процитированных высказываний Нехлюдова видно, что идея кого-либо «исправить» - в качестве ложной - отбрасывается Толстым полностью. Неосуждение же оставляет другого в его самоценном бытии, но оно сохраняет мир, покой также в душе неосуждающего. Ср. название раннего доклада Бахтина «Идея обоснованного покоя» [БАХТИн 2003б].

Кроме того, серия «прощений» в ее различных проявлениях фиксирует состояния духовного разброда «я», от которых «я» пытается отталкиваться, но она может провоцировать все новые и новые кризисы. Искомое Толстым положение духовной гармонии напоминает уже не о Канте, а скорее о ценимых Толстым предшественниках христианства - античных стоиках с их идеалом бесстрастия и, в общем, «неосуждения» других и себя. Сенека отмечал: «поспеши сколько можешь, чтобы подольше наслаждаться совершенством и спокойствием твоей души» [СЕНЕКА].

Хотя Толстой много читал Канта и высоко ценил его [РЕмизОВ 2000; Слоун 2007; GUTSCHE-LEIGHTON 1981], все же в данном случае налицо резкие различия между двумя авторами.

Кантовский постулат, как известно, соотнесен со словами Христа о том, что каждому необходимо поступать так, как он бы хотел, чтобы другие поступали с ним. Но в словах Христа есть только обязательность по отношению к каждому отдельному «я», но нет «закона» для всех (только «благодать»). Именно и только я «один» обязан поступать так-то и так-то (должно). Ср. важное бахтинское замечание: «<..> не понятое Фейербахом требование христианином креста для себя и счастья для других» [БАХТИН 2003б: 329].

Контрастом этому выступает верное напоминание Д. Слоуна о том, что Кант в своей работе «Религия в пределах только разума» «утверждал, что Христос не нужен, поскольку в каждом адекватном человеке заложено божественное начало» [СлОУн 2007: 302-303]. В целом такой кантовский тезис не находит поддержки у Толстого.

Почти единственный пример всепрощения в качестве истинного дара (обмена дарами) у Толстого - в позднем рассказе «Корней Васильев». Здесь прощение разрешает былую вражду и ненависть.

В позднем толстовском рассказе «Алеша Горшок» спокойное смирение героя (полное отсутствие гордыни), стойко сносящего все несправедливости и все испытания таким образом, что он практически не замечает их, а просто живет, честно и спокойно выполняет свои обязанности, вызвано именно неосуждением Алешей мира других. Непонимание данного факта приводит Д. Слоуна к оценке Алеши в качестве якобы «недалекого, глуповатого» и далее, через запятую, следует: «скромного» [СлОун 2007: 307]. Д. Слоуном 
в данной цитате почему-то соположены несопоставимые адъективы; к тому же два первых из них - явно не по адресу ${ }^{4}$.

Алеша настолько чист душой и духом, что у него вообще не возникает необходимости прощать. Он просто никого не осуждает, умирая в своей внутренней светлой гармонии. В этом рассказе неосуждение прямо ставится превыше прощения.

Ситуация этого рассказа заставляет пересмотреть условно-«юридические» аспекты категории вины (в данном случае вины других перед Алешей), когда ответственность мыслится только в горизонте возможного предъявления иска и соответственно последующего «искупления» и «прощения». Р. Ингарден пишет: «Раз о совершенном поступке и о его плохих последствиях помнят, то и вправду за это следует принять ответственность, а также привлечь кого-то к ответственности, поскольку воспоминание определяет относительно направленности и то и другое, как и то, что причиненный вред должен быть перечеркнут» [ИНГАРДЕН 2010: 148-149].

Ингарденовский подход по принципу «предъявления претензий» (в «воспоминании») в качестве основы осознания вины и ответственности - противотолстовский. Алеша Горшок никому не предъявляет претензий (не осуждает), но это не значит, что перед ним никто не несет ответственности. Эту ответственность окружающих осознает нарратор/автор рассказа.

В рассказе Толстого «Божеское и человеческое» о герое-раскольнике, находящемся на каторге и умирающем там, сказано: «то, что над ним ругались смотрители, что на него надевали кандалы, что над ним издевались сотоварищи узники, что все они, так же как и начальство, отреклись от Бога и ругались друг над другом и оскверняли всячески в себе образ Божий, все это не занимало его» [ТОЛстой 1928-1958 т.42: 209]. Раскольник никого не осуждает, поэтому ему незачем и прощать. Находясь в постоянном богатом внутреннем движении, раскольник лишь отстаивает факт своей веры, оставаясь в мире своего самозамкнутого духа, умирая просветленным (хотя это имеет и внешний толчок - проповедь Светлогуба).

Сартр в статье «Экзистенциализм - это гуманизм» повторит кантовский постулат о том, что каждый задает другому правила поведения, но у Сартра он будет практически прямо обращен на «насильственность» сосуществования отдельных экзистенций [САРТР 1991] - ср. вполне закономерный поздний «левацкий» уклон философа.

Примирить подлинную единичность и подлинную всеобщность попытался М.М. Бахтин в своей «Философии поступка»: «единственное место в единственном бытии» («едином и единственном бытии-событии») [БАХТИН 2003а: 19; 35] предполагает диалогизм, оставляя каждого и самим собой, но и в интерсубъективности. Данные бахтинские афоризмы пересекаются с Толстым больше, чем в отталкивающейся от Бахтина идее т.н. «прозаики» К. Эмерсон

4 Это не отменяет, однако, высокой ценности статьи Д. Слоуна. (Возможно также, дело в переводе). 
и Г.С. Морсона [ср. также: ЭмЕРСОН 1995]. Через общий кантовский генезис, его переинтерпретацию - один из путей к сближению Толстого и Бахтина.

Высоко ставивший Канта Толстой пытался строить самой своей жизнью (книгами в меньшей степени) образец для окружающих. Но всей органической суммой своей деятельности он показал существование неразрешимых противоречий между индивидами, хотя и должными стремиться к «общей», «роевой» жизни, но остающимися в своем единичном «я». Тем самым теряется реальность идеи общей модели поведения в виде регулятивной.

Вновь повторим: речь не идет о «лобовом» противопоставлении прощения и неосуждения: между ними достаточно широкие корреляции. Соотнесенное с прощением неосуждение не несет коннотации обязательности для другого, поскольку оно оставляет другого пребыть в его собственном духе. Не осуждая, не уклоняешься от оценки, но оставляешь другого в его мире, а себя в своем. По наблюдению М. Шелера (вполне «толстовскому»), «зло может быть только констатировано» [ШЕЛЕР 1994б: 368].

Идея неосуждения остается у Толстого индивидуалистически-аристократической (данный адъектив совершенно не несет тут никаких «сословных» коннотаций). Единичность не навязывает здесь свои принципы другим, хотя она может «пригласить» другого понять нечто в «я» - но вне кантовских «законов», формализмов поступков и актов сознания.

Бахтин связывает приход Нехлюдова к философии неосуждения с его попыткой «в одиночку освободиться от участия в социальном зле» [БАХТин 2000: 203), а само зло вокруг так и оставить без постороннего вмешательства. Бахтин прав в акцентировании момента «в одиночку», но Толстой вовсе не подразумевает оправдания социального и иного зла. Исследователи уже отмечали, что Толстой не отрицает важности противления злу, он рассуждает о непротивлении злу именно насилием.

Неосуждение делает прощение излишним или ненужным в том плане, что оно уже заведомо не подводит к порогу ненависти, избегает ошибок, долженствующих быть исправленными. Неосуждение - акт «смирения и мужества». Глаза остаются открытыми, они различают добро и зло, фальшь и истину. Только так все становится видимым и слышимым по-настоящему.

Умирающий Иван Ильич перед смертью осуждает окружающих, включая почти всех близких. Но он осуждает параллельно и себя, что можно проинтерпретировать как оставление ситуации пока еще в рамках кантианства с его «цельностью» «круговой поруки». Переходя в мир иной, Иван Ильич никого не прощает, но он отказывается и от осуждения. Венчающий повесть образ «света» вместо смерти - означает приход героя также к неосуждению, т.е. признание собственной бессмертной автономии (как и каждого по отношению к каждому).

Заметна полемичность финального образа «света» в «Смерти Ивана Ильича» по сравнению с описанием самоубийства героини в «Анне Карениной». Хотя идею суда толстовские герои распространяют на самих себя и многое переосмысляют перед кончиной, финалы в двух текстах наполнены по-разному. 
Приходя к обличению мировой фальши накануне и в момент гибели, Анна сначала видит именно свет - это и свет ее прозрения, и свет истины. Он подразумевает отказ от осуждения других через их понимание: «Привычный жест крестного знамения вызвал в душе ее целый ряд девичьих и детских воспоминаний, и вдруг мрак, покрывавший для нее все, разорвался, и жизнь предстала ей на мгновение со всеми ее светлыми прошедшими радостями. Но на не спускала глаз с колес подходящего второго вагона» [ТолСтой 1928-1958 т.19: 348].

И далее, уже после того, как Анна бросилась под колеса поезда: «Она хотела подняться, откинуться; но что-то огромное, неумолимое толкнуло ее в голову и потащило за спину. «Господи, прости мне все!» - проговорила она, чувствуя невозможность борьбы. $<\ldots .>$ И свеча, при которой она читала исполненную тревог, обманов, горя и зла книгу, вспыхнула более ярким, чем когда-нибудь светом, осветила ей все то, что прежде было во мраке, затрещала, стала меркнуть и навсегда потухла» [Толстой 1928-1958 т.19: 348-349].

Прощения своей вины героиня Толстого в конечном счете просит не от других, а от Бога. (Идея «прощения» отчасти закреплена у Толстого за отношением Бога и человека). Предсмертный свет («свеча» - сквозной символ романа; принципиален также образ «мрак разорвался») заслоняется в финале «Анны Карениной» тьмой посмертного состояния. «Исполненная тревог, обманов, горя и зла книга» - это книга жизни. Свеча индивидуального существования Анны гаснет, но книга жизни остается открытой для другого, других.

Очень показательна формула Толстого из его дневников: «Субъективное общечеловеческое» [ТОЛСТОЙ 1928-1958 т.55: 275 (запись от 18 ноября 1906) $]^{5}$. Казалось бы, общечеловеческое должно мыслиться в качестве объективного, но у Толстого оно связано с объединением именно отдельных субъективностей ${ }^{6}$ Имплицитный тезис философии Толстого таков: мир не существует просто в виде общего для всех, он одномоментно мой мир и мир других. Нехлюдову не даруется прощение со стороны Масловой, но она и не осуждает его. Последнее, к чему приходит Нехлюдов - идея недопустимости осуждения ${ }^{7}$.

Непротивление злу насилием и есть неосуждение при полном и всеобъемлющем смотрении, слышании себя и других, мира как одномоментно моего мира и мира других.

5 На эту формулу обратил внимание В.В. Бибихин, но оставил ее без трактовки: [БЕРдяЕВ 1994: 385]. В этой же записи Толстого дается тонкая формула категории сознания: «разум и чувство».

6 Возможные переклички толстовской дневниковой формулы с оценкой субъективности у Гегеля требуют отдельного разговора.

7 «Анна Каренина» и «Воскресение» так или иначе отсылают к «черной» комедии В. Шекспира на адюльтерный сюжет «Мера за меру», само название которой является евангельской реминисценцией, подразумевающей получение индивидом в ответ того же, что он сам заложил. «Мера за меру» заканчивается декларированием идей прощения и неосуждения и носит - до Канта - совершенно антикантианский характер (т.к. основана на идеях милости, а не закона; индивидуальности, а не всеобщности). 
Чтобы понять другого, позволить ему пребыть в его самостоянии, не нужно стремиться поставить себя на его место. Напротив, надо принять позицию другого как самоценную, такую, с которой невозможно тавтологично отождествиться. Налицо сосуществование самых разных и несводимых друг к другу позиций человека в мире. Ж. Делёз в этом плане писал о необходимости постулирования глубинной идеи различия [ДЕЛЁз 1998].

Начинавший в рамках кантианства, Бахтин в своем афоризме о «единственном месте в единственном бытии» («едином и единственном бытии-событии») [БАХТИН 2003a: 19; 35] преодолел Канта (как и в большинстве других своих построений). Бахтин указал своим афоризмом на бесконечное множество «единых и единственных мест», которые никто не может занять, кроме определенного «я». Только собственное «место» (в бытии, в мире, в отношениях с Абсолютным Другим...) и может искать «я». Эта вполне толстовская идея вполне коррелирует с Бахтиным, несмотря на оценку последним Толстого в рамках «монологизма» (полемику с бахтинской трактовкой см. в: [SHUL'TS 2013].

\section{Литература}

БАХТИН 2000: Бахтин, М.М. Идеологический роман Л.Н. Толстого. Предисловие // Бахтин М.М. Собрание сочинений в 7 т. Москва: Русские словари. Т.2.

БАХТИН 2003а: Бахтин, М.М. К философии поступка // Бахтин, М.М. Собрание сочинений в 7 т. Москва: Языки славянской культуры Т.1.

БАХТин 2003б: Бахтин М.М. Проблема обоснованного покоя // Бахтин М.М. Собрание сочинений в 7 т. Москва.: Языки славянской культуры, Т.1.

БЕРДяЕВ 1994: Бердяев, Н.А. Ветхий и Новый завет в религиозном сознании Л. Толстого // Бердяев, Н.А. Философия творчества, культуры и искусства. В 2-х тт. Т.2. Москва: Искусство, 461-482.

БиБихин 2012: Бибихин, В.В. Дневники Л. Толстого. Санкт-Петербург: Издательство Ивана Лимбаха.

ДЕлЁ3 1998: Делёз, Ж. Различие и повторение. Санкт-Петербугр: Петрополис, (пер. с фр. Э.П. Юровской).

ИНГАРДЕН 2010: Ингарден, Р. Книжечка о человеке. Москва: МГУ, (пер. с польск. Е.С. Твердисловой).

КАНТ 1999: Кант, И. Критика практического разума // Кант И. Основы метафизики нравственности. Москва: Мысль, (пер. с нем.).

ПАзолини 2000: Пазолини, П.П. «Сегодня многие считают, что нужно убивать». Интервью Ф. Коломбо // Пазолини, П.П. Теорема. Москва: Ладомир, (пер. с ит. Н. Ставровской).

Ремизов 2000: Ремизов, В.Б. Обретение своего пути (Л. Толстой читает И. Канта и А. Шопенгауэра) // Филологические записки. Воронеж, Вып.15.

РикЁР 2010: Рикёр, П. Путь признания. Москва: РОССПЭН, (пер. с фр.).

САРТP 1991: Сартр, Ж.П. Экзистенциализм - это гуманизм // Сумерки богов. Москва: Политиздат, (пер. с фр.).

СЕНЕКА. Нравственные письма к Луцилию. URL: $\mathrm{http} / /$ royallib.com/read/seneka_lutsiy/nravstvennie_pisma_k_lutsiliyu.html\#o (пер. с лат. С.А. Ошерова). 
Слоун 2007: Слоун, Д. Открытие Канта Толстым // Л. Толстой и мировая культура. Материалы Межд. Научной конференции. Тула: «Ясная Поляна», 299-310.

Толстой 1928-1958: Толстой, Л.Н. Полн. собр. соч. в 90 тт. Москва, 1928-1958.

ХАЙДЕГГЕР 1991: Хайдеггер, М. Разговор на проселочной дороге. Москва: Высшая школа, (пер. с нем. Н.С. Плотникова).

ХАЙДЕГГЕР 1993: Хайдеггер, М. Работы и размышления разных лет. Москва: Гнозис, (пер. с нем. А.В. Михайлова).

ХАЙДЕГГЕР 2006: Хайдеггер, М. Что зовется мышлением? Москва: Территория будущего, (пер. с нем. Э. Сагетдинова).

Худспит 2005: Худспит, С. Преступление, совесть и ответственность в романе Толстого «Воскресение» // Л. Толстой и мировая культура. Материалы Межд. Научной конференции. Тула: «Ясная Поляна», 33-44.

ШЕЛЕР 1994а: Шелер, М. Формализм в этике и материальная этика ценностей // Шелер М. Избранные произведения. Москва: Гнозис, (пер. с нем.).

ШЕЛЕР 1994б: Шелер, М. Ordo amoris // Шелер М. Избранные произведения. Москва: Гнозис, (пер. с нем.).

Шульц 2001: Шульц, С.А. «Записки сумасшедшего» Гоголя и «Записки сумасшедшего» Толстого: топика и нарратив // Гоголезнавчі студіi. Гоголеведческие студии. Ніжин, Вып.7.

Шульц 2002: Шульц, С.А. Историческая поэтика драматургии Л.Н. Толстого (герменевтический аспект). Ростов-на-Дону: Изд-во Ростовского университета,

ЭмЕРСОН 1995: Эмерсон, К. Против закономерности: Соловьев, Шестов, поздний Толстой, ранний Бахтин // Бахтинология. Исследования, переводы, публикации. Санкт-Петербург: Алетейя, 117-131.

Gutsche-LeightON 1981: Jahn, G.R. Tolstoj and Kant // New Perspectives on 19-century Russian Prose / Ed. by G.J. Gutsche and L.G. Leighton. Columbus, Ohio.

SHUL'TS 2013: Shul'ts, S. E. Hemingway and L. Tolstoy // Tolstoy Studies Journal, Vol.XXV.

Сергей Шульц

независимый исследователь

Ростов-на-Дону, Россия

s_shulz@mail.ru; shulcz-70@mail.ru 